\title{
Education of Advanced Practice Nurses in Canada
}

Ruth Martin-Misener, NP, PhD

Associate Professor \& Associate Director, Graduate Programs, School of Nursing Dalhousie University, Halifax, NS

Affiliate Faculty, CHSRF/CIHR Chair Program in Advanced Practice Nursing (APN)

Denise Bryant-Lukosius, RN, PhD

Assistant Professor, School of Nursing \& Department of Oncology, McMaster University Senior Scientist, CHSRF/CIHR Chair Program in APN

Director, Canadian Centre of Excellence in Oncology Advanced Practice Nursing (OAPN) at the Juravinski Cancer Centre

Hamilton, ON

Patricia Harbman, NP-PHC, MN/ACNP Certificate, PhD(c), University of Toronto Graduate student in CHSRF/CIHR Chair Program in APN

Oakville, ON

Faith Donald, NP-PHC, PhD

Associate Professor, Daphne Cockwell School of Nursing, Ryerson University, Toronto, ON Affiliate Faculty, CHSRF/CIHR Chair Program in APN

Sharon Kaasalainen, RN, PhD

Associate Professor, School of Nursing, McMaster University

Career Scientist, Ontario Ministry of Health and Long-Term Care

Affiliate Faculty, CHSRF/CIHR Chair Program in APN

Hamilton, ON

Nancy Carter, RN, PhD

CHSRF Postdoctoral Fellow

Junior Faculty, CHSRF/CIHR Chair Program in APN

McMaster University

Hamilton, ON

Kelley Kilpatrick, RN, PhD

Postdoctoral Fellow, CHSRF/CIHR Chair Program in APN

Professor, Department of Nursing, Université du Québec en Outaouais

St-Jérôme, QC

Alba DiCenso, RN, PhD

CHSRF/CIHR Chair in APN

Director, Ontario Training Centre in Health Services \& Policy Research

Professor, Nursing and Clinical Epidemiology \& Biostatistics, McMaster University

Hamilton, ON 


\begin{abstract}
In Canada, education programs for the clinical nurse specialist (CNS) and nurse practitioner (NP) roles began 40 years ago. NP programs are offered in almost all provinces. Education for the CNS role has occurred through graduate nursing programs generically defined as providing preparation for advanced nursing practice. For this paper, we drew on pertinent sections of a scoping review of the literature and key informant interviews conducted for a decision support synthesis on advanced practice nursing to describe the following: (1) history of advanced practice nursing education in Canada, (2) current status of advanced practice nursing education in Canada, (3) curriculum issues, (4) interprofessional education, (5) resources for education and (6) continuing education. Although national frameworks defining advanced nursing practice and NP competencies provide some direction for education programs, Canada does not have countrywide standards of education for either the NP or CNS role. Inconsistency in the educational requirements for primary healthcare NPs continues to cause significant problems and interferes with interjurisdictional licensing portability. For both CNSs and NPs, there can be a mismatch between a generalized education and specialized practice. The value of interprofessional education in facilitating effective teamwork is emphasized. Recommendations for future directions for advanced practice nursing education are offered.
\end{abstract}

\title{
Introduction
}

Education is essential for securing the future supply of advanced practice nurses (APNs) and for the continued development of those already in the workforce. In Canada, education programs for clinical nurse specialist (CNS) and nurse practitioner (NP) roles began 40 years ago. NPs are "registered nurses with additional educational preparation and experience who possess and demonstrate the competencies to autonomously diagnose, order and interpret diagnostic tests, prescribe pharmaceuticals and perform specific procedures within their legislated scope of practice" (Canadian Nurses Association [CNA] 2008: 16). The CNA defines a CNS as "a registered nurse who holds a master's or doctoral degree in nursing and expertise in a clinical nursing specialty" (CNA 2009: 1).

Both national and international organizations have endorsed graduate education as the entry to practice for APNs (CNA 2008; International Council of Nurses [ICN] 2008). Education was one of the key components examined by the Canadian Nurse Practitioner Initiative (CNPI), a two-year Health Canada-funded project created to develop a framework for the integration and sustainability of the NP role. Programs for CNS and acute care nurse practitioner (ACNP), also known as NP (adult), NP (pediatrics) and NP (neonatal), education are uniformly at the graduate level across Canada. Though in transition, education for the primary 
healthcare nurse practitioner (PHCNP), also known as the NP (family/all-ages) role, currently includes post-baccalaureate and master's programs (Canadian Association of Schools of Nursing [CASN] 2004; Rutherford and Rutherford Consulting Group Inc. 2005). Since the NP is a separately legislated role, education programs require regular formal approval by provincial and territorial regulatory nursing organizations. Matters pertaining to NP education, along with other issues relevant to graduate education, are discussed annually at the Canadian Association of Schools of Nursing Graduate Program Coordinators' Forum during the Association's conference. In follow-up to the report from the CNPI, NP educators from across the country signalled their desire for a national forum to address issues of importance to NP education. Two meetings have been held, and a national listserv was established through the Canadian Association of Schools of Nursing.

According to the CNA (2009: 2), universities "are responsible for preparing CNS roles by providing curricula based on the competencies of advanced nursing practice and by developing innovative programs that facilitate access to graduate education.” The CNA's Advanced Nursing Practice Framework (2008: 14) identifies that graduate credentials alone do not equate with advanced nursing practice and that "It is the combination of graduate education and clinical experience that allows nurses to develop the competencies required in advanced nursing practice." Some Canadian graduate nursing programs include courses in a clinical nursing focus, for example, family, adult, community and mental health. However, while many universities identify that their master's program provides preparation for advanced nursing practice, none have a specifically titled CNS program and, with one exception, do not have specifically titled CNS courses (Personal communication with 27 of 31 universities March 2010). For example, the University of Manitoba offers a Master of Nursing with a cancer focus for advanced practice nurse roles (University of Manitoba Faculty of Nursing 2009).

The aim of this paper is to provide a critical analysis of current advanced practice nursing education in Canada with a view toward what will be needed in the future. We briefly summarize the history of CNS and NP education and examine the current status of education for these roles in relation to curriculum, interprofessional education, resources and continuing education. We conclude with recommendations to promote advanced practice education in Canada.

\section{Methods}

This paper was developed using the results of the scoping review of the literature and key informant and focus group interviews conducted for a decision support synthesis commissioned by the Canadian Health Services Research Foundation (CHSRF) and the Office of Nursing Policy in Health Canada (DiCenso et al. 2010a). The objective was to develop a better understanding of advanced practice 
nursing roles, their current use, and the individual, organizational and health system factors that influence their effective development and integration in the Canadian healthcare system. The synthesis methods included a comprehensive appraisal of published and grey literature on Canadian advanced practice nursing ever published, as well as international literature reviews from 2003 to 2008. After all levels of review, 322 papers representing all Canadian papers (69\% of 468) and recent reviews from other countries were retained in the synthesis. The 62 individual interview participants included 22 APNs, 11 health administrators, 6 provincial government policy makers, 7 nursing regulators, 5 educators, 7 physicians and 4 healthcare team members. Four focus groups were held and attended by a total of 19 participants, who were APNs, educators, administrators and policy makers. A complete description of our methods is provided in an earlier paper in this issue (DiCenso et al. 2010b). For this paper, we focus on articles and key informant interviews that address education.

\section{Results}

History of Advanced Practice Nursing Education in Canada The first Canadian education program for NPs, the Outpost Nursing Program, was initiated in 1967 and offered at Dalhousie University in Halifax until 1997. Its emphasis was on preparation for primary healthcare practice in remote communities (Chaytor Educational Services 1994; Haines 1993; Martin-Misener et al. 1999). Programs at McMaster University in Ontario and in other provinces followed quickly thereafter (Haines 1993; Herbert and Little 1983; Kergin et al. 1973). These early programs were housed in universities and offered post-diploma or post-baccalaureate preparation for what was often referred to as the "expanded role of the nurse" and "family practice nursing" (Advisory Committee on Health Human Resources et al. 2001; Chambers et al. 1974; Jones and Parker 1974; Riley 1974). The McMaster University PHCNP initiative included a program of research to evaluate the NP training and role (Kaasalainen et al. 2010). Despite evidence of the program's success in preparing safe and effective NPs, funding for the education and employment of NPs in all but remote areas virtually disappeared once the physician shortage was resolved (Spitzer 1984). In the 1990s, however, cutbacks in medical residency positions along with a healthcare reform agenda focused on fiscal efficiency and a shift toward community-based care brought renewed government interest in the NP role and funding for NP education in some provinces (DiCenso et al. 2007).

The Council of Ontario University Programs in Nursing (COUPN), a consortium of 10 nursing faculties, developed the COUPN PHCNP Program, which began in the fall of 1995 (Andrusyszyn 1999; Cragg et al. 2003; DiCenso et al. 2003; van Soeren et al. 2000). Funding for the program was provided by the Ontario government and came with a requirement that the program be offered at the post- 
baccalaureate level. The curriculum was developed and offered jointly by 10 schools in French and English, full-time and part-time, distance and on-site, in post-baccalaureate certificate and post-RN baccalaureate programs. These characteristics make it a unique model of NP education in Canada.

The COUPN PHCNP Program was extensively evaluated soon after it began (DiCenso et al. 1997, 1998). The outcome component of the evaluation used a before-after study design with first-year students and program graduates to determine knowledge acquisition in the program. A cohort study compared the knowledge, problem-solving and clinical skills of NP program graduates with secondyear family medicine residents. Knowledge was evaluated using a multiple choice examination, problem solving using the College of Nurses of Ontario's Case Assessment Tool (written case-based short answer test), and clinical skills using six simulated patient scenarios scored by physician-NP teams with controls in place to detect examiner bias.

The study investigators found that NP program graduates' knowledge scores were significantly higher than those of first-year NP students. There was no statistical difference between the NP and resident groups for questions related to obstetrics/ gynecology, psychiatry, prescribing, vaccines/immunization and prevention/health promotion. However, the resident group scored higher than the NP group on medicine and pediatric questions. With respect to problem solving, there was no difference in overall scoring between the two groups; however, the residents scored higher than the NP graduates in health assessment and diagnosis, and the NP graduates scored higher than the residents in health promotion and disease prevention. In terms of clinical skills evaluation, the NP group scored similarly to the family medicine resident group in all six simulated patient scenarios and in interviewing, history taking, counselling, management and physical examination skills.

Soon after the COUPN NP Program was established, other programs followed suit in almost every province. Some programs were initiated at the post-diploma level, some at the post-baccalaureate level and others at the master's level (Rutherford and Rutherford Consulting Group Inc. 2005).

The first ACNP education programs were initiated during the 1980s and 1990s and, in contrast to PHCNP programs, all began at the graduate level (Alcock 1996; Dunn and Nicklin 1995; Haddad 1992). The first ACNP program, designed to train neonatal nurse practitioners, was first offered at McMaster University in 1986. Program development was guided by the results of an interprofessional role definition study (Hunsberger et al. 1992). The educational program was evaluated extensively, both in the form of a before-after study (Mitchell et al. 1995) to ensure that those completing the program had acquired the expected competencies in 
knowledge, problem-solving, communication and clinical skills and in the form of a cohort study (Mitchell et al. 1991) to compare the skills of graduating neonatal NPs with those of pediatric residents.

Recently released statistics from the Canadian Institute for Health Information (CIHI) (2010) show that in 2008, there were 1,626 licensed NPs in Canada. These data do not distinguish between PHCNPs and ACNPs. Of the 1,626 NPs, 597 (36.7\%) had obtained a master's or doctoral degree as their highest education in nursing, 834 (51.3\%) had a baccalaureate degree and 195 (12\%) had a diploma. Compared to the registered nurse workforce, the proportion of NPs with a graduate degree is more than 10 times higher $(36.7 \%$ versus $3.0 \%)$.

The CNS role emerged in Canada and the United States in response to postWorld War II employment and education opportunities (Boone and Kikuchi, as cited in Montemuro 1987). From its inception, graduate education was required for the CNS role and articulated as such in the position statements of professional nursing organizations (Alcock 1996; Montemuro 1987). Although it was not specifically developed to educate CNSs, the first Canadian program offering clinical nursing specialization was the University of Toronto in 1970 (Montemuro 1987). There are limited data about CNSs in Canada (Bryant-Lukosius et al. 2010).

\section{Current Status of Advanced Practice Nursing Education in Canada}

While Canada does not have country-wide standards of education for either the NP or CNS role, two national consensus frameworks of importance to education have been developed: the CNA's Advanced Nursing Practice: A National Framework (2008) and the Canadian Nurse Practitioner Core Competency Framework (CNA 2005). Both provide guidance to the curricula of advanced practice nursing educational programs. Data collected by CNPI provided a comparative analysis of PHCNP and ACNP programs offered in Canadian educational institutions in 2005 (CNPI 2006). At the time, $25 \mathrm{NP}$ programs were offered by 33 educational institutions; of these 25 programs, 13 trained PHCNPs, 9 trained ACNPs and 3 combined PHCNP and ACNP training. Exit credentials from these programs included a post-RN certificate/diploma $(n=3)$, post-baccalaureate certificate/ diploma $(n=2)$, master's $(n=15)$, master's or post-master's diploma/certificate $(n=4)$ and post-master's certificate $(n=1)$. The greatest variability was and continues to be in PHCNP programs.

Realizing the master's degree as the exit credential for PHCNP education has been challenging, though some progress has been made. Barriers have included the reluctance of some governments to fund NP programs at the master's level and the reluctance of institutions without graduate programs to be excluded from offering NP education (Cragg et al. 2003). Nevertheless, the recent Canadian 
nursing literature resounded with the strong endorsement that graduate education was needed to achieve the broad theoretical and clinical knowledge and skill requirements of advanced practice nursing roles and should be the entry to practice requirement (CNA 2008; CNPI 2006; Schreiber et al. 2005a, 2005b). Based on their interviews with graduate prepared nurses when investigating the current understanding of and perceived need for advanced practice nursing in British Columbia, Schreiber et al. (2005a: 14) suggested that "graduate preparation itself contributes to the ability to analyze and practice in complex situations at a sophisticated level." In a second phase of the same qualitative study, participants from diverse stakeholder groups including physicians concluded the complexity of the work required of PHCNPs warranted graduate education (Schreiber et al. 2005b). Similarly, a qualitative study from Australia concluded graduate education was needed for NPs to meet the demands of the role and foster the credibility of their preparedness for the role (Gardner et al. 2006).

Interview participants in our synthesis differed in their views about the educational requirements for PHCNPs. An APN participant explained how the knowledge acquired during graduate education enables NPs to practise autonomously and to offer comprehensive patient care services in this way:

I have worked with very many of the nurse practitioners who are advanced certificate-prepared and they're good, but it only extends to a certain role, basically very much focused on the diagnosis and treatment. When you get into the true population health community development perspective, they lack.... What the master's brings to people is the complete picture. I've noticed sitting in with a few different nurse practitioners when I was doing my own education to see the difference, and I saw a total difference between a master's-prepared and a certificateprepared $[\mathrm{NP}]$ just in how they approached it, the completeness they brought to the interaction with the patient and the follow-ups.

Many educator, regulator and administrator participants and some government participants talked about the legitimacy and credibility graduate education provides. Some linked graduate education with the ability to practise autonomously with a broad scope of practice. The following quote illustrates this.

Primary care is clearly recognized across the country as a significant problem.... So on the advice of many we positioned our primary care nurse practitioners to have a very wide prescriptive and diagnostic authority, which meant they had to have a really rigorous education program at the master's level. 
In contrast, other interview participants indicated that the push to move PHCNP education to the master's level was misguided. Although intended to benefit NPs, it was unlikely to improve patient care or healthcare system efficiency. Some government informants stated they did not support graduate education for PHCNPs because it was unjustified by evidence. The longer program reduced the number of NPs in the system, and the higher tuition costs were likely to lead to higher salary demands by NPs, without concomitant increases in their accessibility and number of patients served.

While not arguing against graduate education, several authors (CNPI 2006; Schreiber et al. 2005a, 2005b) identified that the requirement of graduate education for PHCNPs was a concern for northern jurisdictions because of the limited access to graduate education in rural and remote communities. This is an important concern since only $5.9 \%$ of all registered nurses practising in rural and remote areas are APNs (Stewart et al. 2005). Although master's NP programming is available by distance education from several universities, accessibility has been confounded by other factors such as competing demands in the workplace, technological challenges and other difficulties related to geographical remoteness (CNPI 2006; Tilleczek et al. 2005). Our interview participants also identified the importance of distance education for both CNS and NP roles, explaining that family and financial obligations limited their mobility, and voiced similar concerns about the accessibility of educational programs. Despite these challenges, some northern jurisdictions indicated they envisioned having at least one PHCNP in each remote community by 2010 (Northwest Territories Health and Social Services 2004). In addition to distance education, another strategy some northern educational institutions are using is to forge collaborations with universities to enable master's level PHCNP education to be offered using a combination of face-to-face and distance modalities (Registered Nurses Association of Northwest Territories and Nunavut 2009).

Regulators, educators and government informants in our synthesis reported that inconsistency in educational requirements was continuing to cause significant problems, especially when education was tied to licensing. For example, NPs educated at the post-baccalaureate level were not able to become licensed in British Columbia or Quebec. Several interview participants referred to imminent changes through the Agreement of Internal Trade that would enable NP mobility across Canadian jurisdictions by prohibiting discrimination on the basis of educational preparation. For the most part, this was regarded as positive for NPs, although some interview participants were concerned about the potential outmigration of NPs from provinces that paid lower salaries. 
A review from the United States indicated CNS programs there are expanding (Fulton and Baldwin 2004). In our study, CNS education was discussed most often by APN interview participants. The following quotes from three APNs from different provinces convey concerns about the absence of programs specific to the CNS role.

I have concerns at the education level about how CNSs are being able to access their education. [University] master's program used to have a CNS role. Now they have one course on advanced practice. They have a whole NP program, but if you want to become a CNS it's becoming more and more difficult to get that kind of system-thinking, system-support level of education to be able to understand where your role is at the systems level.

Well, my understanding is that there aren't that many master's programs that have a CNS stream. Now they're being developed as an advanced practice nursing role - that's the stream. It's [CNS] no longer a clinical specialty that you develop at the master's level of preparation and that's unfortunate.

The key concern around the CNS role which is of grave concern to me is the lack of specific education for the CNS role. There used to be programs that had a very well designed course content that would prepare them for evaluation, for project management, for the whole piece of work at the systems level, policy, developing policy and protocols. All of those pieces are not necessarily lumped together in a nice package so that when you come out you can really step out in the role and fly, and in the United States there are some of those educational programs directed for the CNS. There were in Canada, but there aren't anymore.

One educator interview participant indicated that progress toward development of a CNS educational stream was being made at one Canadian university. The following quote describes this innovation and how program developers have distinguished CNS and NP education.

We've had various meetings with the CNS community to work with them to be part of the educational programs. We've ramped up. We've actually changed some of our core courses from advanced practice nursing courses to CNS courses. We've done lots of marketing to help nurses make distinctions. We've held information nights to help potential candidates make distinctions between how they might choose what sort of role they were going for. We do it in a visual image that shows a triangle with system knowledge and research inquiry and direct patient care skills and [we] really demonstrate that this pyramid, this triangle, is diametrically 
opposite. What a CNS [and NP] learn. The thing at the top of the pyramid of the one is at the bottom of the pyramid for the other, and vice versa. So that educationally they are very differently prepared and the roles that they're going to take are very different.

\section{Curriculum Issues}

A number of papers identified a need for national curriculum standards and a consistent core curriculum for both NP and CNS programs (CASN 2004; CNA 2006, 2008; CNPI 2006; Olson 2004; Schreiber et al. 2005a). The rationale for improved consistency, coherence and alignment of educational programs was to enhance the credibility and visibility of NP and CNS roles, improve their integration into healthcare systems, facilitate better use of NP and CNS resources and enable labour mobility. Many interview participants echoed this, as reflected in the following comment from an administrator.

There probably needs to be a national standardization, or some sort of process to look at accreditation, standardization of programs.

Other participants signalled their caution that curriculum standardization should not be so rigid that it impeded creativity and innovation. As one American educator commented,

CNS education is pretty diverse and needs to come together a little bit more around what are the standards for educating CNSs. Where in my opinion, as an educator, the nurse practitioners stuff is too contrived, it is lock step standard curriculum. You need curricular standards; you don't need a standardized curriculum. It makes it hard to try and change, to be able to adapt and adjust, if you've locked yourself in to a standardized curriculum.

The CNPI's (2006) review of the curricula of NP programs across Canada identified some commonalities in the types of courses that were included, such as health assessment, pathophysiology and management of health and disease, including prescribing. It did not assess differences or commonalities in the content or methods of appraisal used in these courses. The CNPI review reported inconsistencies among educational programs in the types of core graduate theoretical courses being offered, the balance between theory and clinical experience, and program length. Differences in program length were attributed to whether the program was a master's or not, the former being consistently two years in length and the latter 12 months. A recent review of the university calendars of 24 Canadian master's nursing programs found the number of research course requirements ranged from one to three, and one program had no mandatory research course (J. Ritchie, personal communication, March 23, 2009). In some programs the 
number of required research courses varied according to thesis, course-based and NP streams. This review did not include a comparison of curriculum content related to the leadership, consultation, collaboration and education components of advanced practice nursing.

Making decisions about what to include in education programs for entry level practice and, more importantly, what to leave out, has been a long-standing challenge (Martin-Misener et al. 1999). Our interview participants suggested the addition of a variety of topics to the curricula, such as more in-depth pathophysiology, conflict resolution, APN-physician collaboration, government lobbying, political navigation, writing job descriptions and a final formal residency or internship. At the same time, as reflected in the following quotes from an administrator and APN, they expressed concerns about program length and the balance between clinical experience and theory.

Education was viewed as a long process that may not meet the needs of the work setting where a large number of credits were related to research and less on the actual role in the setting.

Nothing is long enough, if you want to learn everything, and some things are too long, students will tell you.

Although there was support for the distinctiveness of CNS and NP roles (Urquhart et al. 2004) and the importance of having a match between advanced practice nursing education and role expectations in the practice setting (Roots and MacDonald 2008), the Canadian literature was silent on the debate about the merits or lack thereof of a shared curriculum for different types of APNs. The literature from the United States highlighted some commonalities in the CNS and NP roles, but reflected divergent perspectives about whether a shared educational curriculum was desirable (Carper and Haas 2006; Chan and Garbez 2006; Goudreau et al. 2007; Stark 2006).

The comments from our interview participants supported a need for educational curricula specific for CNS, ACNP and PHCNP roles. Educator and physician participants commented on the limited availability of NP programs in some parts of the country, resulting in situations where NPs educated for primary healthcare were employed and expected to have the skill set to practise in a specialized ACNP role. The result was "not that great of a fit." Government participants from different provinces added that inadequate communication about NP roles and competencies contributed to the discordance between education and ACNP positions. 
A similar problem was identified about the CNS role by ACNP and administrator participants. They commented that CNSs obtain generic master's degrees in nursing but practise with specialized populations without a certification process or protected titling. Consequently, there are a number of nurses prepared at the graduate level with clinical specialization who address the components of the CNS role and yet are not titled CNS. At the same time, as the following quote illustrates, the lack of precision in the education and titling of CNSs means that anyone with a master's degree in nursing can claim to be a CNS.

They think that just because they have a master's degree means they can be a CNS. And so that is a problem within all of the nursing community. Nurse practitioner education is very specific - you graduate with your NP.... As a CNS, it's not that specific. What is the education for a CNS? I don't know. How do you get to be a CNS? Lots of people would say, "I don't know."

Thus both the non-CNS titled nurse in the role of a CNS, and the indiscriminate use of the CNS title, contribute to role confusion within and outside the profession. Improvements are needed in how the role is described and how the title is controlled (Bryant-Lukosius et al. 2010).

\section{Interprofessional Education}

The value of interprofessional education in facilitating effective teamwork was a consistent theme in the literature (Barrett et al. 2007; Jones and Way 2004; van Soeren et al. 2007). It is supported by both nursing and medical associations (Canadian Medical Protective Association and Canadian Nurse Protective Society 2005; CNA 2003; Ontario Medical Association and Registered Nurses Association of Ontario 2003) and educational institutions (CASN 2004; Pringle et al. 2000). Writing specifically about NPs and physicians, Bailey et al. (2006) identified synergistic decision making and bi-directional consultation and referral as hallmarks of optimal collaboration but acknowledged collaboration of this calibre was not easily achieved, even with education. They recommended more research to understand the effectiveness of education interventions.

Many interview participants also spoke of the importance of interprofessional education. They identified a need for more interprofessional learning opportunities among health disciplines, commenting that "students need to be learning together." The following quotes from an administrator and educator emphasize the value of interprofessional education to enable advanced practice nursing and other health professional students to learn about and trust in the capabilities of each other's roles. 
I think within the healthcare system just educating about the role as part of the clinical education process and trying to ensure that physicians and others have an opportunity to have interprofessional placement opportunities as part of their education would be a critical factor.

I think if there was more interprofessional education so that there was a better understanding of who does what, how and why and trust in it [interprofessional collaboration would improve]. Part of this is about trust that they really know what they are doing. You could do this with some of the physical assessment stuff; there are ways you could thread things through common shared knowledge.

\section{Resources for Education}

The literature (Cross and Goodyear 2004; Cummings and McLennan 2005; Lachance 2005) and key informants concurred that funding for advanced practice nursing education was insufficient, resulting in implications for students, faculty and programming. Educators and administrators expressed concern over the cost of NP education and low earning potential of NPs in some jurisdictions, explaining that it could create recruitment challenges. Physician, regulator and administrator participants recommended support in the form of student bursaries; some indicated NP students were already being supported financially.

The need for funding to develop faculty, preceptors and mentors to teach advanced practice nursing students and to support role socialization was stressed in the literature (CNPI 2006; Goudreau et al. 2007; Schreiber et al. 2003; 2005a; van Soeren et al. 2007). Competition for clinical placements and physician time to train both medical residents and ACNPs was another concern (Fédération des médecins résidents du Québec 2004). We found one Canadian study that evaluated NP education from a cost perspective. Kushner (1976) reported on the economic returns of the McMaster University program, concluding that NP education was profitable from the point of view of the student since costs were recuperated within two years of program completion. The introduction of NPs was desirable from a societal point of view in that the rate of return on the investment in the program exceeded the rate of social discount, and the investment was profitable to the government if the NP stayed in the workforce 30 years (Kushner 1976).

Many of our interview participants expressed concerns about whether clinical placement sites would be able to support the learning needs of all the various types of students who require this experience as part of their educational program. They indicated that there was already competition for clinical placements and expected this to be exacerbated by increasing numbers and types of students. Participants called for better mentorship opportunities for advanced 
practice nursing students and stressed the importance of having academically and clinically qualified faculty and preceptors. Many indicated a need to recruit more faculty and strategic planning to ensure a supply of qualified faculty to meet the needs of advanced practice nursing programs.

Interview participants did not comment specifically on the cost of education, except to acknowledge it was resource intensive. Some participants recommended sharing academic resources across universities throughout the country, as well as intra-university sharing among the various health disciplines. The following quote offered by an educator exemplifies this idea.

We're looking at a limited number of graduate students and limited numbers of faculty, and so I think there may be ways to deliver some of the programs in different ways and I think there needs to be cooperation across the country.

\section{Continuing Education}

The importance of ongoing learning and removal of barriers to continuing education for NPs was evident in the Canadian literature (CNPI 2006; Donald et al. 2009). The lack of opportunity for relevant continuing education was a challenge for NPs in long-term care (Stolee et al. 2006) and remote settings (Martin-Misener et al. 2008). Tilleczek et al. (2005) found face-to-face learning venues were valued by all NPs, but rural and northern NPs found distance modalities useful because of travel and distance constraints. Other barriers to continuing education were difficulty taking time off work, insufficient resources, family responsibilities, lack of information regarding the availability of courses, geographical barriers, fatigue, unsatisfactory previous learning experiences (Centre for Rural and Northern Health Research 2006) and the lack of faculty (Schreiber et al. 2003, 2005a).

Interview participants echoed findings from the literature commenting on both the importance of continuing education and barriers to it, as the following quote from a physician demonstrates.

Our APNs need more attention paid, in my opinion, to their continuing professional development - their ongoing education. I mean that's important for all healthcare personnel, but it's especially important for these people. Most often they're in leadership positions either because it's written down on paper or simply because they command the leadership because of their abilities. It is important that they keep up with what is going on.

Educator interview participants added that lack of funding impeded their delivery of continuing education. Regulator interview participants supported a compre- 
hensive plan for continuing education for APNs and called attention to the need for additional education for NPs who provide care for patients with urgent and emergent conditions in remote settings, where there are few resources. CNS interview participants advocated for improved continuing education for CNSs in remote settings, highlighting it as a retention strategy.

\section{Discussion}

Canada is not unique in its struggle to move forward with advanced practice nursing roles and education reforms. Worldwide, countries are endeavouring to define NP roles and establish educational standards (ICN 2008; Royal College of Nursing 2008; Sheer and Wong 2008). Justifying the need for advanced education for the PHCNP role is a recurrent challenge (Gardner et al. 2006). Globally, nursing organizations have recommended that the educational standard for APNs be a graduate degree (Pulcini et al. 2010). While there has been some progress toward attaining this goal in Canada, discrepancies persist in the educational requirements for PHCNPs. Two provinces (Newfoundland and Labrador, and Saskatchewan) continue to offer PHCNP education programs at less than a graduate level. While Ontario has prepared PHCNPs at the post-baccalaureate level for many years, this is in transition with all universities that offer PHCNP education now offering graduate courses. Given this, it is unlikely that Canada will realize master's education for all APNs by the close of 2010, as the CNPI hoped; perhaps the fallback goal of 2015 will be achieved.

Furthermore, the quest to realize master's education for all NPs is occurring in a context in which most other disciplines in the health professions have established a master's or doctorate degree as their requirement for entry to practice. Just to the south, in the United States, the doctorate of nursing practice (DNP) will become the entry level credential for APNs by 2015. The DNP differs from a $\mathrm{PhD}$ in that its focus is advanced clinical education, whereas the focus of a $\mathrm{PhD}$ is advanced research preparation. The discussion about the advantages and disadvantages of DNP education for the Canadian context has begun (Acorn et al. 2009; Joachim 2008; Nelson 2008). However, given that master's level preparation for all NPs in Canada has yet to be achieved, it is difficult to see how a case for doctoral preparation could be argued convincingly or successfully at the present time.

Clearly there are still significant challenges to overcome. Governments persistently demand evidence to support the need for higher education for PHCNPs and so far have not been convinced by the consensus-based 
expert opinion studies that exist. There are also concerns that higher training requirements will increase the expense, and reduce the health human resource benefit, of NPs when regarded as substitutive healthcare professionals (Evans et al. 2010).

Our scoping review and key informant interviews identified a number of issues related to advanced practice nursing program access and curricula. There is a tension between the length of advanced practice nursing programs and the development of the full range of advanced practice nursing competencies - clinical, research, leadership, consultation and collaboration (CNA 2008). According to the CNA's Advanced Nursing Practice: A National Framework (2008: 23) "generating, synthesizing and using research evidence is central to advanced nursing practice," and APNs are able to "as either primary investigator or collaborator with other members of the healthcare team or community, identify, conduct and support research that enhances or benefits nursing practice." Despite these aims, APNs consistently report that research is the most underdeveloped aspect of their role (Bryant-Lukosius et al. 2004, 2007). The findings from our study raise questions about what the research content of an advanced practice nursing curriculum should include and whether it should be the same for all advanced practice nursing roles. In addition, while there is clear support for inter-professional education, the knowledge base that underpins and guides the best practices for interprofessional education in advanced practice nursing education requires further development. As the evidence base of pedagogical effectiveness expands, advanced practice nursing curricula will need to respond accordingly. This and the push for increased efficiencies in education, accessible distance education opportunities and improved clinical training for APNs will challenge the creativity and flexibility of program planners.

Another important finding of our synthesis was that for both CNSs and NPs, there can be a mismatch between a generalized education and specialized practice. Universities in the United States offer specialty and subspecialty education during entry level master's programs (Richmond and Becker 2005). It is unclear how much specialty education a country the size of Canada, with its relatively small number of APNs can support, especially since specialty education requires substantial resources not only at the university level but also for credentialling and certification (CNA 2006; CNPI 2006). The Canadian examinations for NPs, which many provinces and territories have incorporated into their licensing processes, include family/all ages (primary healthcare), adults, pediatrics and neonatal. While 
primary healthcare and neonatal are defined specialized areas of practice, adult and pediatric descriptors are broader.

Still, creative solutions to the challenge of access to specialty education have emerged that may have wider application. For instance, the consortium distance model to education used by COUPN has proven to be an effective approach to PHCNP education in Ontario (Andrusyszyn et al. 1999; Baxter et al. 2009; Cragg et al. 2003; van Soeren et al. 2000, 2003). Such a model could be adapted and applied to address other education needs including specialization. Another example of a partnership approach is the specialized interprofessional psychosocial oncology education courses offered to a national audience by faculty from multiple institutions using distance technology (www.ipode.ca). This model is particularly attractive from a costeffectiveness perspective when the specialty area is small and could potentially be replicated for other specialties.

For the time being, the limited access to specialty education in Canada means that NPs and CNSs may be working in clinical areas in which they initially do not have specialized knowledge and skills. Given this reality, mentorship is a role development support that could be further exploited to enhance specialized knowledge acquisition. The Ontario oncology advanced practice nursing mentorship program is an example of an interprofessional mentorship program accessible by distance modalities throughout Ontario (http://apn.webexone.com/login.asp?loc=\&link). Continuing education is another means of enabling APNs to develop and maintain specialist knowledge and stay up-to-date with current evidence-informed practice. However, attention to the barriers associated with the delivery of and accessibility to continuing education for APNs is needed.

A multidisciplinary roundtable convened by CHSRF formulated evidenceinformed policy and practice recommendations based on the synthesis findings. All of their recommendations are reported in an earlier paper in this issue (DiCenso et al. 2010b). Specifically pertinent to advanced practice nursing education are the following: (1) a pan-Canadian approach should be taken to standardize advanced practice nursing educational standards, requirements and processes, and (2) the curricula across all health professions should address interprofessionalism (DiCenso et al. 2010b). These recommendations mirror those of the CNPI (2006) and resemble those of American scholars who have argued for reforms that will lead to standardization of education programs and accreditation or other regular review 
processes (Hanson and Hamric 2003; Olson 2004). The most convincing argument for moving forward on these recommendations is the potential impact it could have on patient care. We need to be able to determine and provide the best possible education for the various types of advanced practice nursing roles so that these roles can best meet the needs of patients and healthcare organizations (Bryant-Lukosius and DiCenso 2004).

The environment in which all of these changes and challenges are happening is fiscally constrained. That said, an ongoing supply of qualified faculty, preceptors and appropriate clinical placements is essential for Canadian programs to educate safe, competent practitioners. These are scarce resources and careful planning is needed to ensure there will be sufficient numbers to meet the learning needs of future generations of APNs. For students, the high cost of education, especially in lengthy programs, may affect recruitment and retention, particularly when taking into account lost salary and unattractive earnings post-graduation. Provincial and territorial financial support for advanced practice nursing programs varies across the country, though our synthesis did not investigate this specifically. Comparisons of the financial support for the education of various health professionals, particularly newly introduced professionals, are not available. Such information could be useful for determining the equity of funding across programs.

How then should we move forward on the findings of the synthesis and CHSRF roundtable recommendations? The CNPI was an extraordinary panCanadian example of what can be accomplished when the combined efforts of multiple sectors, resources and champions use a systematic, evidencebased approach to achieve a common goal. Surely the way forward is to find a way to build on this model. Because leadership in nursing education is the mandate of the Canadian Association of Schools of Nursing, this organization is well positioned to take the initiative to move this agenda forward in partnership with other national organizations such as the Canadian Association of Advanced Practice Nurses, the CNA and the Office of Nursing Policy, as well as provincial regulatory bodies and academic institutions. Further development of advanced practice nursing education is critical for ensuring that Canadians nationwide receive accessible healthcare of the highest quality. We know what needs to be done. The time has come for all of us to step up to the plate and make it happen. 


\section{Acknowledgements}

The synthesis from which this work was derived was made possible through joint funding by the Canadian Health Services Research Foundation and the Office of Nursing Policy of Health Canada. We thank the librarians who conducted searches of the electronic databases, Tom Flemming at McMaster University and Angella Lambrou at McGill University. Chris Cotoi and Rick Parrish in the Health Information Research Unit (HIRU) at McMaster University created the electronic literature extraction tool for the project. We thank all those who took time from their busy schedules to participate in key informant interviews and focus groups. The following staff members provided excellent support: Heather Baxter, Renee Charbonneau-Smith, R. James McKinlay, Dianna Pasic, Julie Vohra, Rose Vonau, and Brandi Wasyluk. Special thanks go to our advisory board, roundtable participants and Dr. Brian Hutchison for their thoughtful feedback and suggestions.

\section{References}

Acorn, S., K. LaMarche and M. Edwards. 2009. "Practice Doctorates in Nursing: Developing Nursing Leaders." Canadian Journal of Nursing Leadership 22(2): 85-91. Retrieved October 10, 2009. $<$ http://www.longwoods.com/content/20801>.

Advisory Committee on Health Human Resources and The Centre for Nursing Studies in collaboration with The Institute for the Advancement of Public Policy, Inc. 2001. Final Report: The Nature of the Extended/Expanded Nursing Role in Canada. Retrieved January 12, 2009. <http://www.cns.nf.ca/ research/finalreport.htm>.

Alcock, D.S. 1996. "The Clinical Nurse Specialist, Clinical Nurse Specialist/Nurse Practitioner and Other Titled Nurse in Ontario." Canadian Journal of Nursing Administration 9(1): 23-44.

Andrusyszyn, M.A., M. van Soeren, H. Spence Laschinger, D. Goldenberg and A. DiCenso. 1999. "Evaluation of Distance Education Delivery Methods for a Primary Care Nurse Practitioner Program." Journal of Distance Education 14(1): 14-33.

Bailey, P., L. Jones and D. Way, 2006. "Family Physician/Nurse Practitioner: Stories of Collaboration.” Journal of Advanced Nursing 53(4): 381-91.

Barrett, J., V. Curran, L. Glynn and M. Godwin. 2007. CHSRF Synthesis: Interprofessional Collaboration and Quality Primary Healthcare. Ottawa, ON: Canadian Health Services Research Foundation. Retrieved December 30, 2010. <http://www.chsrf.ca/Migrated/PDF/ SynthesisReport_E_FINAL.pdf $>$.

Baxter, P., A. DiCenso, R. Martin-Misener and D. Bryant- Lukosius. 2009. An Evaluation of the Ontario Primary Health Care Nurse Practitioner Governance Structure. Moncton, NB: Canadian Association Schools of Nursing Research Conference. Presented May 7, 2009.

Bryant-Lukosius, D. and A. DiCenso. 2004. "A Framework for the Introduction and Evaluation of Advanced Practice Nursing Roles." Journal of Advanced Nursing 48(5): 530-40.

Bryant-Lukosius, D., E. Green, M. Fitch, G. Macartney, L. Robb-Blenderman, S. McFarlane, K. Bosompra, A. DiCenso, S. Matthews and H. Milne. 2007. "A Survey of Oncology Advanced Practice Nurses in Ontario: Profile and Predictors of Job Satisfaction." Canadian Journal of Nursing Leadership 20(2): 50-68. Retrieved June 1, 2009. <http://www.longwoods.com/content/18902>.

Bryant-Lukosius, D., N. Carter, K. Kilpatrick, R. Martin-Misener, F. Donald, S. Kaasalainen, P. Harbman, I. Bourgeault and A. DiCenso. 2010. “The Clinical Nurse Specialist Role in Canada.” Canadian Journal of Nursing Leadership 23(Special Issue December): 140-66.

Canadian Association of Schools of Nursing. 2004. Report on the CASN/FNIHB Workshop on Primary Health Care/Nurse Practitioner Education. Ottawa, ON: CASN. Retrieved March 2, 2009. $<\mathrm{http} / / /$ casn.4poyntzdezign.com/media.php?mid=64>. 
Canadian Institute for Health Information. 2010. Regulated Nurses: Canadian Trends 2004 to 2008. Ottawa, ON: CIHI. Retrieved March 21, 2010. <http://secure.cihi.ca/cihiweb/products/regulated_ nurses_2004_2008_en.pdf >.

Canadian Medical Protective Association and Canadian Nurse Protective Society. 2005. Canadian Medical Protective Association /Canadian Nurse Protective Society Joint Statement on Liability Protection for Nurse Practitioners and Physicians in Collaborative Practice. Ottawa, ON: Canadian Medical Protective Association and Canadian Nurse Protective Society. Retrieved March 9, 2009. $<$ www.cnps.ca/joint_statement/joint_statement_e.html>.

Canadian Nurses Association. 2003. Joint Position Statement. Scopes of Practice. Ottawa, ON: CNA. Retrieved March 2, 2009. <http://www.cna-aiic.ca/CNA/documents/pdf/publications/PS66_Scopes_ of_practice_June_2003_e.pdf $>$.

Canadian Nurses Association. 2005. Canadian Nurse Practitioner Core Competency Framework. Ottawa, ON: CNA. Retrieved March 2, 2009. < http://www.rnantnu.ca/Portals/0/Documents/ Registration\%202007/NP\%20Application/CNPE_Core_Competency_Framework_e.pdf > .

Canadian Nurses Association. 2006. Report of 2005 Dialogue on Advanced Nursing Practice. Ottawa, ON: CNA. Retrieved March 2, 2009. <http://www.cna-aiic.ca/CNA/documents/pdf/publications/ Report_2005_ANP_Dialogue_e.pdf>.

Canadian Nurses Association. 2008. Advanced Nursing Practice: A National Framework. Ottawa, ON: CNA. Retrieved January 12, 2009. <http://www.cna-aiic.ca/CNA/documents/pdf/publications/ ANP_National_Framework_e.pdf $>$.

Canadian Nurses Association. 2009. Position Statement: Clinical Nurse Specialist. Ottawa, ON: CNA. Retrieved September 3, 2009. <http://www.cna-aiic.ca/CNA/documents/pdf/publications/PS104_ Clinical_Nurse_Specialist_e.pdf $>$.

Canadian Nurse Practitioner Initiative. 2006. Nurse Practitioners: The Time Is Now Technical Reports. Ottawa, ON: CNPI, CNA. Retrieved August 12, 2009.<http://www.cna-aiic.ca/CNA/practice/ advanced/initiative/evaluation/default_e.aspx $>$.

Carper, E. and M. Haas. 2006. "Advanced Practice Nursing in Radiation Oncology." Seminars in Oncology Nursing 22(4): 203-11.

Centre for Rural and Northern Health Research. 2006. Primary Health Care Nurse Practitioner 2006 Tracking Study. Sudbury, ON: Laurentian University.

Chambers, L.W., B. Suttie and V. Summers. 1974. "Expanded Role Nurses: An Education Program in Newfoundland and Labrador." Canadian Journal of Public Health. Revue Canadienne de Santé Publique 65(4): 273-6.

Chan, G.K. and R.O. Garbez. 2006. "Education of Advanced Practice Nurses for Emergency Care Settings: Emphasizing Shared Competencies and Domains." Advanced Emergency Nursing Journal 28(3): 216-25.

Chaytor Educational Services. 1994. Preparing for Outpost Practice: An Evaluation of the Outpost and Community Health Nursing Program at Dalhousie University. Halifax, NS: Chaytor Educational Services.

Cragg, C.E., S. Doucette and J. Humbert. 2003. “Ten Universities, One Program: Successful Collaboration to Educate Nurse Practitioners." Nurse Educator 28(5): 227-31.

Cross, S. and R. Goodyear. 2004. "The Advanced Practice Nurse: Global Transition through Incrementalism.” Nursing and Health Policy Review 3(2): 111-28.

Cummings, G. and M. McLennan. 2005. "Advanced Practice Nursing: Leadership to Effect Policy Change.” Journal of Nursing Administration 35(2): 61-6.

DiCenso, A., S. Sidani, D. Irvine, H. Laschinger, M.A. Andrusyszyn, A. Gafni, B. Hutchison, G. Guyatt, S. Walter, V. Bhatia and S. Caty. 1997. Nurse Practitioner Evaluation Project: Evaluation of the NP Educational Program 1996-1997. Hamilton, ON: McMaster University.

DiCenso, A., S. Sidani, D. Irvine, H. Laschinger, M.A. Andrusyszyn, A. Gafni, B. Hutchison, G. Guyatt, S. Walter, V. Bhatia and S. Caty. 1998. Nurse Practitioner Evaluation Project: Evaluation of the NP Educational Program 1997-1998. Hamilton, ON: McMaster University. 
DiCenso, A., G. Paech and IBM Corporation. 2003. Report on the Integration of Primary Health Care Nurse Practitioners into the Province of Ontario. Toronto, ON: Ontario Ministry of Health and LongTerm Care. Retrieved January 12, 2009. <http://www.health.gov.on.ca/english/public/pub/ministry_reports/nurseprac03/nurseprac03_mn.html >.

DiCenso, A., L. Auffrey, D. Bryant-Lukosius, F. Donald, R. Martin-Misener, S. Matthews and J. Opsteen. 2007. "Primary Health Care Nurse Practitioners in Canada." Contemporary Nurse 26(1): $104-15$.

DiCenso, A., D. Bryant- Lukosius, I. Bourgeault, R. Martin-Misener, F. Donald, J. Abelson, S. Kaasalainen, K. Kilpatrick, S. Kioke, N. Carter and P. Harbman. 2010a. Clinical Nurse Specialists and Nurse Practitioners in Canada: A Decision Support Synthesis. Ottawa, ON: CHSRF. Retrieved December 30, 2010. <http://www.chsrf.ca/SearchResultsNews/10-06-01/b9cb9576-6140-4954-aa572b81c1350936.aspx $>$.

DiCenso, A., R. Martin-Misener, D. Bryant-Lukosius, I. Bourgeault, K. Kilpatrick, F. Donald, S. Kaasalainen, P. Harbman, N. Carter, S. Kioke, J. Abelson, R.J. McKinlay, D. Pasic, B. Wasyluk, J. Vohra and R. Charbonneau-Smith. 2010b. "Advanced Practice Nursing in Canada: Overview of a Decision Support Synthesis." Canadian Journal of Nursing Leadership 23(Special Issue December): 15-34.

Donald, F., P. Baxter, A. DiCenso, J. Opsteen, R. Martin-Misener, R. Pong and C. Sloan. 2009, September 30 to October 2. Continuing Education for Primary Health Care Nurse Practitioners in Ontario: Survey Results. Oral Presentation. Canadian Association of Advanced Practice Nurses Conference, St. John's, NL.

Dunn, K. and W. Nicklin. 1995. “The Status of Advanced Nursing Roles in Canadian Teaching Hospitals." Canadian Journal of Nursing Administration 8(1): 111-35.

Evans, R.G., D. Schneider, M. Barer and S. Morgan. 2010. Health Human Resources Productivity: What It Is, How It's Measured, Why (How You Measure) It Matters, and Who's Thinking about It. Ottawa, ON: Canadian Health Services Research Foundation and Michael Smith Foundation for Health Research. Retrieved December 30, 2010. <http://www.chsrf.ca/Migrated/PDF/ ResearchReports/CommissionedResearch/HHRP_en_FINAL.pdf $>$.

Fédération des médecins résidents du Québec. 2004. Avis consultatif de la FMRQ déposé dans le cadre des activités du comité conjoint consultatif paritaire OIIQ-CMQ concernant la création du rôle de l'infirmière praticienne spécialisée en cardiologie - volet cardiologie médicale au Québec. Montreal, PQ: Fédération des médecins résidents du Québec.

Fulton, J.S. and K. Baldwin. 2004. "An Annotated Bibliography Reflecting CNS Practice and Outcomes." Clinical Nurse Specialist 18(1): 21-39.

Gardner, G., S. Dunn, J. Carryer and A. Gardner. 2006. "Competency and Capability: Imperative for Nurse Practitioner Education.” Australian Journal of Advanced Nursing 24(1): 8.

Goudreau, K.A., K. Baldwin, A. Clark, J. Fulton, B. Lyon, T. Murray, J.E. Rust, S. Sendelbach, and the National Association of Clinical Nurse Specialists. 2007. "A Vision of the Future for Clinical Nurse Specialists: Prepared by the National Association of Clinical Nurse Specialists, July 2007." Clinical Nurse Specialist 21(6): 310-20.

Haddad, B. 1992. “Report on the Expanded Role Nurse Project." Canadian Journal of Nursing Administration 5(4): 10-7.

Haines, J. 1993. The Nurse Practitioner - A Discussion Paper. Ottawa, ON: Canadian Nurses Association.

Hanson, C.M., and A.B. Hamric. 2003. "Reflections on the Continuing Evolution of Advanced Practice Nursing." Nursing Outlook 5(5): 203-11.

Herbert, F.A. and C. Little. 1983. "Nurse Practitioner Program: University of Alberta." Canadian Medical Association Journal 128(11): 1311-2.

Hunsberger, M., A. Mitchell, S. Blatz, B. Paes, J. Pinelli, D. Southwell, S. French and R. Soluk. 1992. "Definition of an Advanced Nursing Practice Role in the NICU: The Clinical Nurse Specialist/ Neonatal Practitioner." Clinical Nurse Specialist 6(2): 91-6. 
International Council of Nurses. 2008. The Scope of Practice, Standards and Competencies of the Advanced Practice Nurse. Geneva: International Council of Nurses.

Joachim, G. 2008. “The Practice Doctorate: Where Do Canadian Nursing Leaders Stand?" Canadian Journal of Nursing Leadership 21(4): 42-51. Retrieved October 4, 2009. <http://www.longwoods.com/ content/20286>.

Jones, P.E. and N.I. Parker. 1974. "Education for the Nurse in Primary Health Care." Nursing Papers 6(2): 57-64.

Jones, L. and D. Way. 2004. Practice Component: Literature Review Report. Delivering Primary Health Care to Canadians: Nurse Practitioners and Physicians in Collaboration. Ottawa, ON: CNA and CNPI. Retrieved March 2, 2009. <http://206.191.29.104/documents/pdf/Models_of_Collaboration_ Literature_Review_e.pdf $>$.

Kaasalainen, S., R. Martin-Misener, K. Kilpatrick, P. Harbman, D. Bryant-Lukosius, F. Donald, N. Carter and A. DiCenso. 2010. "A Historical Overview of the Development of Advanced Practice Nursing Roles in Canada." Canadian Journal of Nursing Leadership 23(Special Issue December): 35-60.

Kergin, D.J., M.A. Yoshida, W.O. Spitzer, J.E. Davis and E.M. Buzzell. 1973. “Changing Nursing Practice through Education." Canadian Nurse 69(4): 28-31.

Kushner, J. 1976. "A Benefit-Cost Analysis of Nurse Practitioner Training." Canadian Journal of Public Health. Revue Canadienne de Santé Publique 67(5): 405-9.

Lachance, K. 2005. “The 2004 Schering Lecture. Are Advanced Practice Nurses (APNs) Here to Stay? The APN in the Oncology Setting." Canadian Oncology Nursing Journal 15(2): 96-100, 106.

Martin-Misener, R., A. Vukic and R. May. 1999. “Lessons Learned from the Dalhousie Outpost Nursing Program.” In W. Ramp, J. Kulig, I. Townshend and V. McGowan, eds., Health in Rural Settings: Contexts for Action, pp. 2003-10. Lethbridge, AB: University of Lethbridge.

Martin-Misener, R., M.L. MacLeod, K. Banks, A.M. Morton, C. Vogt and D. Bentham. 2008. “There's Rural, and Then There's Rural: Advice from Nurses Providing Primary Healthcare in Northern Remote Communities." Canadian Journal of Nursing Leadership 21(3): 54-63. Retrieved March 1, 2009. <http://www.longwoods.com/content/20062>.

Mitchell, A., J. Watts, R. Whyte, S. Blatz, G. R. Norman, G. H. Guyatt, D. Southwell, M. Hunsberger and B. Paes. 1991. "Evaluation of Graduating Neonatal Nurse Practitioners." Pediatrics 88(4): 789-94.

Mitchell, A., J. Watts, R. Whyte, S. Blatz, G.R. Norman, D. Southwell, M. Hunsberger, B. Paes and J. Pinelli. 1995. "Evaluation of an Educational Program to Prepare Neonatal Nurse Practitioners." The Journal of Nursing Education 34(6): 286-9.

Montemuro, M.A. 1987. “The Evolution of the Clinical Nurse Specialist: Response to the Challenge of Professional Nursing Practice." Clinical Nurse Specialist 1(3): 106-10.

Nelson, S. 2008. "Commentary: Yet Another Fork in the Road? Nursing Doctoral Education in Canada." Canadian Journal of Nursing Leadership 21(4): 52-55. Retrieved October 4, 2009. <http:// www.longwoods.com/content/20287>.

Northwest Territories Health and Social Services. 2004. Framework for Action-Primary Health Care Nurse Practitioner. Yellowknife, NWT: Northwest Territories Health and Social Services. Retrieved January 12, 2009. <http://www.hlthss.gov.nt.ca/pdf/reports/human_resources/2004/english/nurse_ practitioner_framework_for_action.pdf $>$.

Olson, T. 2004. "Spasm or Transformation? Advanced Practice Psychiatric Nursing Education in the United States." International Journal of Psychiatric Nursing Research 10(1): 1152-63.

Ontario Medical Association and Registered Nurses Association of Ontario. 2003. The RN(EC)-GP Relationship: A Good Beginning. Toronto: Ontario Medical Association and Registered Nurses Association of Ontario. Retrieved January 16, 2009. <http://www.rnao.org/Storage/12/712_RNAO_ OMA_Report.pdf $>$.

Pringle, D., C. Levitt, M.E. Horsburgh, R. Wilson and M. Whittaker. 2000. "Interdisciplinary Collaboration and Primary Healthcare Reform: Statement from the Ontario Chairs of Family Medicine and the Council of Ontario University Programs in Nursing." Canadian Family Physician 46: $763-5$. 
Pulcini, J., M. Jelic, R. Gul and A. Loke. 2010. “An International Survey on Advanced Practice Nursing Education, Practice, and Regulation." Journal of Nursing Scholarship 41(1):31-9.

Registered Nurses Association of Northwest Territories and Nunavut. 2009. Spring Newsletter. Yellowknife, NWT: Registered Nurses Association of Northwest Territories and Nunavut. Retrieved September 7, 2009. <http://www.rnantnu.ca/>.

Richmond, T.S. and D. Becker. 2005. "Creating an Advanced Practice Nurse-Friendly Culture: A Marathon, Not a Sprint." AACN Clinical Issues 16(1): 58-66.

Riley, I. 1974. “The B.Sc.(N) Graduate as a Nurse Practitioner.” Nursing Papers 6(2): 19-20.

Roots, A. and M. MacDonald. 2008, September 17-20, 2008. 3 Years Down the Road: Exploring the Implementation of the NP Role in British Columbia, Canada. Poster presented at the Toronto: 5th International Council of Nursing, International Nurse Practitioner/Advanced Practice Nursing (INP/APN) Conference.

Royal College of Nursing. 2008. Advanced Nurse Practitioners - An RCN Guide to the Advanced Nurse Practitioner Role, Competencies and Programme Accreditation. London: Royal College of Nursing. Retrieved March 2, 2009. <http://www.rcn.org.uk/_data/assets/pdf_file/0003/146478/003207.pdf>.

Rutherford, G. and Rutherford Consulting Group Inc. 2005. Education Component: Literature Review Report. Ottawa: Canadian Nurses Association and Canadian Nurse Practitioner Initiative. Retrieved March 2, 2009. <http://www.cna-aiic.ca/CNA/documents/pdf/publications/cnpi/tech-report/ section5/03_Education_AppendixB.pdf $>$.

Schreiber, R., H. Davidson, M. MacDonald, J. Crickmore, L. Moss, J. Pinelli, S. Regan, B. Pauly and C. Hammond. 2003. Advanced Nursing Practice: Opportunities and Challenges in British Columbia. Retrieved December 30, 2010. <http://www.chsrf.ca/Migrated/PDF/ResearchReports/OGC/ schreiber_report.pdf $>$.

Schreiber, R., M. MacDonald, B. Pauly, H. Davidson, J. Crickmore, L. Moss, J. Pinelli and S. Regan. 2005a. "Singing from the Same Songbook: The Future of Advanced Nursing Practice in British Columbia." Canadian Journal of Nursing Leadership 18(2) <http://www.longwoods.com/ content/19027>.

Schreiber, R., M. MacDonald, B. Pauly, H. Davidson, J. Crickmore, L. Moss, J. Pinelli, S. Regan and C. Hammond. 2005b. "Singing in Different Keys: Enactment of Advanced Nursing Practice in British Columbia.” Canadian Journal of Nursing Leadership 18(2)<http://www.longwoods.com/ content/19026>.

Sheer, B. and F.K. Wong. 2008. "The Development of Advanced Nursing Practice Globally." Journal of Nursing Scholarship 40(3): 204-11.

Spitzer, W.O. 1984. “The Nurse Practitioner Revisited: Slow Death of a Good Idea." New England Journal of Medicine 310(16): 1049-51.

Stark, S.W. 2006. “The Effects of Master's Degree Education on the Role Choices, Role Flexibility, and Practice Settings of Clinical Nurse Specialists and Nurse Practitioners." Journal of Nursing Education 45(1): 7-15.

Stewart, N.J., C. D’Arcy, J.R. Pitblado, D.G. Morgan, D. Forbes, G. Remus, B. Smith, M.E. Andrews, J. Kosteniuk, J.C. Kulig and M.L.P. MacLeod. 2005. "A Profile of Registered Nurses in Rural and Remote Canada." The Canadian Journal of Nursing Research. Revue Canadienne de Recherche en Sciences Infirmières 37(1): 122-45.

Stolee, P., L.M. Hillier, J. Esbaugh, N. Griffiths and M.J. Borrie. 2006. "Examining the Nurse Practitioner Role in Long-Term Care: Evaluation of a Pilot Project in Canada." Journal of Gerontological Nursing 32(10): 28-36.

Tilleczek, K., R. Pong and S. Caty. 2005. "Innovations and Issues in the Delivery of Continuing Education to Nurse Practitioners in Rural and Northern Communities." Canadian Journal of Nursing Research 37(1): 146-62.

University of Manitoba, Faculty of Nursing. 2009. Master of Nursing (Cancer Focus). Retrieved September 22, 2009. <http://umanitoba.ca/faculties/nursing/chsrf-cihr/313.htm>. 
Urquhart, G., S. Roschkov, D. Rebeyka and K. Scherr. 2004. “Clinical Nurse Specialist or Nurse Practitioner?" Canadian Nurse 100(5): 18-22.

van Soeren, M.H., M.A. Andrusyszyn, H. Laschinger, D. Goldenberg and A. DiCenso. 2000.

"Consortium Approach for Nurse Practitioner Education." Journal of Advanced Nursing, 32(4): 825-33.

van Soeren, M., M.A. Andrusyszyn, A. DiCenso and E. Staples. 2003. "Innovations in Nurse Practitioner Education through a Consortium and Distance Education." In T. Guberski, ed., Teaching and Technology in Nurse Practitioner Education. New Paradigms in Advanced Nursing Practice pp. 91-5. Washington, DC: National Organization of Nurse Practitioner Faculties.

van Soeren, M., B. Fraser and J. Sanders. 2007. NP Roles in Ontario: Looking to the Future. The Accord Project - Briefing Paper. Retrieved January 12, 2009. Toronto, ON: Nurse Practitioners' Association of Ontario. <http://www.npao.org/Uploads/public/Accord\%20Project\%20Briefing\%20Paper.pdf $>$. 